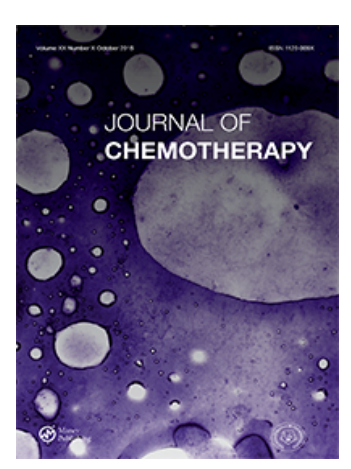

\title{
Journal of Chemotherapy
}

\section{Cell wall composition and biofilm formation of azoles-susceptible and -resistant Candida glabrata strains}

\author{
Alberto Vitali, Elisabetta Vavala, Valeria Marzano, Claudia Leone, Massimo \\ Castagnola, Federica lavarone \& Letizia Angiolella
}

To cite this article: Alberto Vitali, Elisabetta Vavala, Valeria Marzano, Claudia Leone, Massimo Castagnola, Federica lavarone \& Letizia Angiolella (2016): Cell wall composition and biofilm formation of azoles-susceptible and -resistant Candida glabrata strains, Journal of Chemotherapy, DOI: 10.1080/1120009X.2016.1199507

To link to this article: http://dx.doi.org/10.1080/1120009X.2016.1199507

View supplementary material \lceil

Published online: 20 Jul 2016.

Submit your article to this journal

Q View related articles $\widetilde{ }$

View Crossmark data $\nearrow$ 


\title{
Cell wall composition and biofilm formation of azoles-susceptible and -resistant Candida glabrata strains
}

\author{
Alberto Vitali ${ }^{1}$, Elisabetta Vavala ${ }^{2}$, Valeria Marzano ${ }^{3}$, Claudia Leone ${ }^{2}$, \\ Massimo Castagnola 3 , Federica lavarone ${ }^{3}$, Letizia Angiolella ${ }^{2}$
}

${ }^{1}$ CNR-ICRM, C/o Institute of Biochemistry and Clinical Biochemistry, Catholic University, Largo F. Vito 1, Rome 00168, Italy, ${ }^{2}$ Department of Public Health and Infectious Diseases, "Sapienza” University of Rome, P.le Aldo Moro 5, Rome 00161, Italy, 3 Institute of Biochemistry and Clinical Biochemistry, Catholic University, Largo F. Vito 1, Rome 00168, Italy

In the present study, three strains of Candida glabrata have been investigated to shed light on the mechanisms involved in azole resistance during adherence and biofilm formation. In particular, a clinical isolate, susceptible to azole-based drugs, DSY562 and two different resistant mutagenic strains deriving from DSY562, SFY114 and SFY115, have been analysed with different approaches for their cell wall composition and properties. A proteomic analysis revealed that the expression of six cell wall-related proteins and biofilm formation varied between the strains. The SFY114 and SFY115 strains resulted to be less hydrophobic than the susceptible parental counterpart DSY562, on the other hand they showed a higher amount in total cell wall polysaccharides fraction in the total cell wall. Accordingly to the results obtained from the hydrophobicity and adherence assays, in the resistant strain SFY115 the biofilm formation decreased compared to the parental strain DSY562. Finally, the total glucose amount in resistant SFY115 was about halved in comparison to other strains. Taken together all these data suggest that azole drugs may affect the cell wall composition of C. glabrata, in relation to the different pathogenic behaviours.

Keywords: Proteomic, Cell wall, Drug-resistance, Adherence, Biofilm, Hydrophobicity, Polysaccharides, Candida glabrata

\section{Introduction}

Compared to other Candida species, Candida glabrata has recently emerged as the second most common cause in human of mucosal and disseminated candidiasis. ${ }^{1}$ C. glabrata is a haploid yeast accounting for approximately the $15 \%$ of all Candida infections worldwide, particularly the bloodstream ones, ${ }^{2,3}$ in which the formation of hyphae or pseudohyphae during colonization or tissue infection has not been observed. Several studies suggest that nosocomial acquisition of $C$. glabrata is quite common and may be due to exogenous factors. Moreover, two major risk factors associated with C. glabrata colonization are the prolonged duration of hospitalization and previous antimicrobial treatments. ${ }^{4}$ Additionally, the haploid nature of C. glabrata genome makes the pathogen especially well suited for acquiring and expressing multi drug resistance (MDR) traits in the presence of drug pressure ${ }^{5}$ rendering its eradication particularly hard to achieve. Recent surveillance data have revealed an increase of $C$. glabrata clinical isolates that display resistance to not only azoles, but also to the echinocandin-class of antifungals drugs inhibiting

Correspondence to: Letizia Angiolella, Department of Public Health and Infectious Diseases, "Sapienza" University of Rome, P.le Aldo Moro 5, Rome 00161, Italy. Email: letizia.angiolella@uniroma1.it cell wall biosynthesis. ${ }^{6}$ Comparably to other pathogenic Candida species, the cell wall of Candida glabrata is the point of contact between host and fungus. The cell wall components mediate tissue adhesion and invasion, give protection against host defence reactions, trigger the host immune response and may also confer resistance to antifungal drugs. ${ }^{7,8}$ Common to many other fungi, the central core of their cell wall is a branched $\beta-(1-3), \beta-(1-6)$ glucan connected to chitin, acting as a linker to outer cell wall mannoprotein. The outer glycoprotein layer of the fungal cell wall plays a major role in host recognition. ${ }^{9}$ The primary event in Candida infection is the adhesion to host surfaces, which is required for initial colonization and subsequent biofilm formation. The adherence of micro-organisms to surfaces involves numerous factors such as the expression of specific cell surface glycoproteins. ${ }^{10}$ Yeast cell surface hydrophobicity (CSH) is involved in the adherence process of yeasts, for the presence of hydrophobic proteins embedded in the cell wall matrix ${ }^{11,12}$ beneath an outer fibrillary layer. In C. glabrata, these cellcell adhesive interactions are mediated by a set of cell surface adhesins encoded by the EPA (epithelial adhesin) gene family. Several of the EPA proteins are significant for adherence and virulence. ${ }^{13}$ Indeed, C. glabrata EPA1 
is up-regulated during early stages of adhesion to human epithelial cells, ${ }^{14,15}$ whereas EPA6 is expressed during biofilm development. ${ }^{16,17}$ C. glabrata lacks the yeast-to-hyphae transition, a crucial phenomenon during C. albicans biofilm development as this morphogenesis is required to create a thick three-dimensional structure. ${ }^{18}$ In spite of this, C. glabrata is able to form biofilms with a typical architecture, characterized by a thick network of yeast cells embedded in the extracellular material ${ }^{19}$ rich in proteins and carbohydrates as reported by Silva et al. ${ }^{20}$.

In the present study, we investigate from different points of view the differences between drug-resistant and drug-susceptible strains of $C$. glabrata, analysing the polysaccharide composition of the cell wall and its protein content through a proteomic approach, and measuring the cell surface hydrophobicity, the adherence and the biofilm formation.

\section{Materials and methods Chemicals}

All reagents were purchased from Sigma-Aldrich (Milan, Italy) unless otherwise stated. Solution and chromatographic eluent were made with deionized water with a specific resistance of $18.2 \mathrm{M} \Omega \cdot \mathrm{cm}$ (Water Purification System, P-nix PowerIScholar;Human Corporation, Seul, Korea). Acetonitrile (ACN) and Formic Acid (FA) were obtained from Merck KGaA (Darmstadt, Germany).

\section{Strains and growth conditions}

Three strains of Candida glabrata have been object of this study: DSY562, a clinical isolate, susceptible to azoles (DSY562 Oropharynx; 8, 0.125, $0.125 \mu \mathrm{g} / \mathrm{ml}$ MIC of Fluconazole, Itraconazole and Ketoconazole, respectively) and two mutagenic strains deriving from the parental strain DSY562 resistant to azoles: SFY114 (>64 $\mu \mathrm{g} /$ ml) (DSY562 pdr1D-PDR1) and SFY115 (DSY562 pdr1D-L280F). ${ }^{21}$ Each strain was routinely maintained on Sabouraud Dextrose Agar (2\%) medium (SDA; Difco, Detroit, MI; USA) at $28^{\circ} \mathrm{C}$.

\section{Cell wall protein preparation}

For all the experimental purposes, the strains were grown on yeast nitrogen base medium (Y.N.B.; Difco) supplemented with $0.1 \%$ glucose, at $28{ }^{\circ} \mathrm{C}$. Cell wall preparations were carried out as previously described. ${ }^{22}$ Cell walls were suspended in $0.05 \mathrm{M}$ Tris- $\mathrm{HCl} \mathrm{pH} 6.8$ buffer containing $50 \mathrm{mM}$ Dithiothreitol (DTT), $1 \mathrm{mM}$ Phenylmethyl sulfonyl-fluoride (PMSF) and $20 \mathrm{Units} / \mathrm{ml}$ of a purified $\beta$-1,3 Glucanase (Zymolyase 100T; Seikagaku Kogyo Co. Ltd, Tokyo, Japan). After incubation at $37^{\circ} \mathrm{C}$, the solution containing the digested walls was centrifuged and the supernatant, containing the released proteins, was precipitated by adding 4 volumes of cold absolute Ethanol $\left(4{ }^{\circ} \mathrm{C}\right.$, overnight). Proteins obtained by this procedure will be referred to as CWPs (cell wall proteins). Two biological replicates were carried out for each sample.

\section{Two-dimensional gel electrophoresis (2-DE) and image analysis}

CWPs pellets were dissolved in rehydration buffer containing $6 \mathrm{M}$ Urea, $2 \mathrm{M}$ Thiourea, 4\% CHAPS, $15 \mathrm{mM}$ DTT, 0.2\% Bio-Lyte 3/10 Ampholyte (Bio-Rad Laboratories, Hercules, CA, USA) and the protein concentration was detected using a 2-D Quant kit (Amersham Biosciences, Uppsala, Sweden). For the first dimension, $100 \mu \mathrm{g}$ of total proteins, with trace amounts of bromophenol blue, were loaded onto $\mathrm{pH}$ 3-10 nonlinear $11 \mathrm{~cm}$ gel IPG strips (Ready Strip; Bio-Rad) and isoelectric focusing was performed using a Protean IEF Cell (Bio-Rad) running the samples at $20^{\circ} \mathrm{C}$ a total final voltage of $35 \mathrm{kVh}$. Isoelectric focused strip gels were incubated for $15 \mathrm{~min}$ in equilibration solution (6 M Urea, 50 mMTris- $\mathrm{HCl}$ pH 8.8, 30\% Glycerol, 2\% Sodium dodecyl sulphate (SDS), 0.002\% Bromophenol blue) with $1 \%$ dithiothreitol (DTT) and then for 15 min with 4\% Iodoacetamide (IAA). The second-dimension separation was performed on $12 \%$ BisTris Criterion-XT precast gels (11 cm; Bio-Rad) using a Criterion Cell apparatus (Bio-Rad). 2-D gels were stained with colloidal Coomassie Blue stain ${ }^{23}$ and scanned with a GS-800 Calibrated Densitometer (Bio-Rad). The images were analysed using PDQuest software (version 7.0.1; Bio-Rad) and subsequently three high-quality gels for each strain were chosen, being the choice based on protein spot resolution and number, to allow experimental statistical comparison. The CWPs 2-DE gels were compared using the DSY562 strain as a control. Following to automatic background subtraction, spot detection and spot filtering, a reference gel was selected from one of the experimental gels. Then, unmatched protein spots of the remaining gels were manually added to this reference gel to create the master gel, a virtual image comprehensive of all matched spots derived from all analysed samples. The matching of spots between gels was manually reviewed and optical density of protein spots was quantified, in order to perform a differential analysis of protein patterns. The gels were collected in three separated groups (DSY562, SFY114 and SFY115), and for each detected spot the average optical density value \pm standard deviation in each group was determined. The ratio of the mean normalized spot intensity of resistant vs. susceptible samples was calculated for the spots identified in the replicates of strains gel deriving from each yeast. Only spots with a $p<0.05$, according to the T Student's test, were accepted.

\section{Protein identification}

Spots of interest were manually excised from 2-DE gels and destained with $25 \mathrm{mM}$ ammonium bicarbonate $\left(\mathrm{NH}_{4} \mathrm{HCO}_{3}\right)$ / ACN 1:1 (v/v), dehydrated with $100 \%$ ACN, reduced with $10 \mathrm{mM}$ DTT in $25 \mathrm{mM} \mathrm{NH}_{4} \mathrm{HCO}_{3}$ and alkylated with $55 \mathrm{mM}$ IAA in $25 \mathrm{mM} \mathrm{NH}_{4} \mathrm{HCO}_{3}$. After complete dehydration, a solution of $0.01 \mu \mathrm{g} / \mu \mathrm{L}$ porcine methylated Trypsin (Promega, Madison, WI, USA) in $25 \mathrm{mM} \mathrm{NH} \mathrm{HCO}_{3}$ was added, and 
proteins were digested at $37^{\circ} \mathrm{C}$ overnight. The reaction was stopped by adding trifluoroacetic acid (TFA) at a final concentration of $0.1 \%$. The supernatants containing tryptic peptides were collected along with peptide fragments extracted from the spot gel with $100 \%$ ACN/0.1\% TFA in water 3:2 $(\mathrm{v} / \mathrm{v})$. Tryptic peptides were evaporated, then dissolved in $0.1 \%$ FA and analysed by liquid chromatography-electrospray ionization tandem mass spectrometry (LC-ESI-MS/ MS) on an Ultimate 3000 Micro HPLC apparatus (Dionex, Sunnyvale, CA, USA) equipped with a FLM-3000-Flow manager module, directly coupled to a LTQ Orbitrap XL hybrid FT mass spectrometer (Thermo Fisher Scientific, Waltham, MA, USA). Reverse-phase chromatography was performed on a Discovery Bio Wide Pore C18 column ( $3 \mu \mathrm{m}$ particle diameter; column dimension $1 \mathrm{~mm} \mathrm{id} \times 10 \mathrm{~cm}$; Supelco Park, Bellefonte, PA, USA) at a flow rate of $80 \mu \mathrm{L} /$ min, using the following eluents: (A) $0.056 \%(\mathrm{v} / \mathrm{v}$ ) aqueous FA and (B) acetonitrile: water, 80:20 with $0.05 \%$ (v/v) aqueous FA. The applied gradient was linear from 0 to $50 \%$ of solvent B in $60 \mathrm{~min}$. The LTQ-Orbitrap mass spectrometer was operated in a data-dependent mode in which each full mass spectrometric (MS) scan (mass range 300-2000 Da, 60,000 resolving power) was followed by data dependent fragmentation experiments (MS/MS) of the three most abundant multiple-charged precursor ions acquired in the linear trap quadrupole via by collision-induced dissociation using a normalized collision energy of $35 \%$. Tandem mass spectra were analysed by Proteome Discoverer program (version 1.4.1; Thermo Fisher Scientific), using the embedded ion accounting algorithm (Sequest HT) as search engine against UniProt KB Protein Knowledgebase (release 2014_02 of 19 February 14 containing 542503 sequence entries; taxonomical restriction: Candida glabrata, 5195 sequence entries). The search parameters were $10 \mathrm{ppm}$ tolerance for precursor ions and 0.6 Da for product ions, 1 missed cleavage and carbamydomethylation of cysteine as fixed modification, oxidation of methionine as variable modification and on a decoy database search calculated false discovery rate (FDR) under 5\%.

\section{Adherence assay and biofilm formation}

Cells were grown for $24 \mathrm{~h}$ at $28{ }^{\circ} \mathrm{C}$ in a $1 \%$ yeast extract, $2 \%$ peptone, $2 \%$ dextrose (YPD) broth, washed twice with sterile PBS (10 mM phosphate buffer, $2.7 \mathrm{mM}$ potassium chloride, $137 \mathrm{mM}$ sodium chloride, $\mathrm{pH}$ 7.4) and then suspended in RPMI 1640 supplemented with morpholine propane sulfonic acid (MOPS) at $1.5 \times 10^{3}$ cells $/ \mathrm{ml}$. After incubation for $3 \mathrm{~h}$ at $37^{\circ} \mathrm{C}$ in six-well polystyrene plates (Corning Incorporated, Corning, NY) followed by extensive washing, $1 \mathrm{ml}$ of Sabouraud dextrose agar (SDA) was poured into each well and let solidify. After incubation for $24 \mathrm{~h}$ at $37^{\circ} \mathrm{C}$, colonies were counted and the results were expressed as a percentage of the inoculum. The inoculum size for each cell suspension was confirmed by plating aliquots of the culture directly in SDA plates. For biofilm formation, cells grown as above were seeded at a density of $1 \times 10^{6}$ cells $/ \mathrm{ml}$ in pre-sterilized, polystyrene, flat bottom six-well microtiter plates (Corning, N.Y) and incubated for $48 \mathrm{~h}$ at $37^{\circ} \mathrm{C}$. After biofilm formation, the medium was aspirated and non-adherent cells were removed, carefully washing the biofilms three times with sterile PBS. A semi quantitative measurement of metabolic activity of biofilm formation was made by $\mathrm{CV}$ assay, ${ }^{24}$ the biofilms were fixed with $99 \% \mathrm{v} / \mathrm{v}$ methanol for $15 \mathrm{~min}$, and then $0.02 \%(\mathrm{v} / \mathrm{v})$ $\mathrm{CV}$ was added for $20 \mathrm{~min}$. Biofilms were washed and 33\% (v/v) acetic acid was added again for $30 \mathrm{~min}$. The CV released was measured at $590 \mathrm{~nm}$. Biofilm cultures were grown in triplicate and each assay performed three times.

\section{Hydrophobicity assay}

Hydrophobicity levels of the cell surface were determined by a two-phase system. ${ }^{7}$ The cells were grown on SDA for $24 \mathrm{~h}$ at $28{ }^{\circ} \mathrm{C}$. Liquid YEPD medium (2\% Peptone, $1 \%$ Yeast extract and $2 \%$ glucose), was inoculated with cells at a starting OD600 of 0.08 and subsequently cultured at $30^{\circ} \mathrm{C}$. Cells were harvested during exponential growth (OD600 of 2) or after $24 \mathrm{~h}$, when all glucose had been consumed. The cells were washed with sterile saline buffer and afterwards suspended at a concentration of $2 \times 10^{6}$ cells $/ \mathrm{ml}$ in sodium phosphate buffer $0.05 \mathrm{M}, \mathrm{pH}$ 7.2. Then, $3 \mathrm{ml}$ of the cell suspension were transferred into a glass tube containing $500 \mu \mathrm{l}$ octane and mixed for $1 \mathrm{~min}$ by moderate vortexing. After the separation of the phases, the aqueous phase was carefully transferred to a cuvette and the OD600 was measured. Each value is the average of three independent biological replicas for each strain, with five measurements per individual cell culture.

\section{Determination of dry weight and polysaccharide content}

For dry weight determination, cells grown for $24 \mathrm{~h}$ at $30{ }^{\circ} \mathrm{C}$ under shaking were used. Each culture $(50 \mathrm{ml})$ was filtered through $0.45-\mu \mathrm{m}$ membrane filters (Millipore). Filters were washed with $50 \mathrm{ml}$ of distilled water and dried for $12 \mathrm{~h}$ at $80^{\circ} \mathrm{C}$, and the dry weight was calculated for each strain. Each assay was performed in triplicate. For determination of alkali-acid-soluble and insoluble cell wall components, the strains DSY562, SFY114 and SFY115 were grown in YPD broth for $24 \mathrm{~h}$ at $28{ }^{\circ} \mathrm{C}$. The cells were hydrolyzed as described by Fleet and Manners. ${ }^{25,26}$ An aliquot of the cells were treated with $0.5 \mathrm{M}$ acetic acid for $3 \mathrm{~h}$ at $60{ }^{\circ} \mathrm{C}$ and centrifuged. Then, the resultant pellet was treated with $0.5 \mathrm{M} \mathrm{NaOH}$ for $6 \mathrm{~h}$ at $90{ }^{\circ} \mathrm{C}$. The insoluble residue was treated with $20 \mathrm{U} / \mathrm{ml}$ of a purified ß-1, 3 Glucanase (Zymolyase 100T) overnight at $37^{\circ} \mathrm{C}$. Carbohydrates were assayed by the method described by Dubois et al. ${ }^{27}$

\section{Statistical analysis}

All experiments were performed in triplicates and values presented are the mean with standard deviation, obtained from three different observations. Student's t-test was used for statistical analysis and a value of $p<0.05$ was 


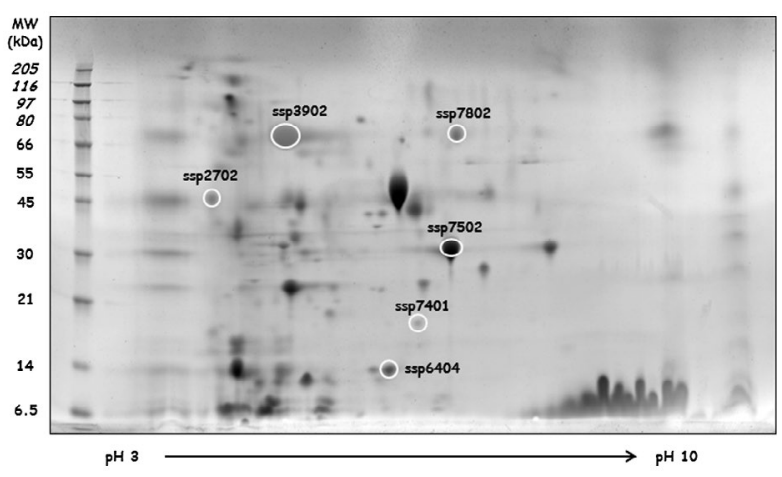

Figure 1 2-DE gel of DSY562 strain, used as a reference for all the three kind of samples. CWPs were loaded on immobilized non-linear $\mathrm{pH}$ gradients strips in the horizontal dimension followed by sodium dodecyl sulphate-polyacrylamide gelsin the vertical dimension. The gels were visualized by colloidal Coomassie staining. Marked protein spots were differentially expressed in azoles-resistant and -susceptible C. glabrata strains. SSP, Standard Spot number, is the number assigned by PDQuest software to each master gel spot.

considered statistically significant $(*)$ and $p<0.001$ as highly significant $(* *)$ for comparisons. ${ }^{28}$

\section{Results}

\section{Proteomic analysis}

To gain insight into the mechanisms involved in azole resistance, we analysed different aspects of the cell wall composition of three selected strains of Candida glabrata: DSY562, an azole susceptible clinical isolate; SFY114 and SFY115, two different resistant mutagenic strains deriving from DSY562. Cell wall preparations of the three strains were analysed by means of 2-DE mapping in order to investigate the differential expression of CWPs between azoles-susceptible and -resistant yeasts. Equal amounts of each CWPs extract were submitted to 2-DE electrophoresis; multiple gels were run for each sample and one representative gel deriving from the control strain DSY562, was used as a reference 2-DE map (Fig. 1). Image and statistical analysis were performed by PDQuest software and analysed as reported in experimental section. Six proteins showed statistically significant variability in the expression pattern between the samples (Fig. 1 and Table 1). The corresponding spots were excised from 2-DE gels, digested with trypsin and subjected to mass spectrometry analysis. LC-ESI-MS/MS investigation lead to their identification and Gene Ontology (GO) classification as listed in Table 1. The cell wall proteins Q6FTZ7 (ssp7502: being ssp the standard spot number as assigned by the PDQuest software) and Q6FUQ9 (ssp7802) resulted up-regulated in the SFY114 strain, while they were down-regulated in the SFY115 strain in a similar fashion, as shown in Fig. 2. Q6FTS0 (ssp2702), a protein similar to Saccharomyces cerevisiae BGL2 (Soluble cell wall protein 9; Glucan 1, 3-beta-glucosidase), was up-regulated in SFY115 while in SFY114 was at control level. The phosphoglycerate-mutase Q6FUX8 (ssp6404) appeared down-regulated both in
SFY114 and SFY115 more evidently in the second strain. Likewise, the superoxide dismutase Q6FWL5 (ssp7401) was down-regulated in both resistant strains with major effect in SFY115. The Lysophospholipase 1 Q6FTS0 (ssp2702) was down-regulated in SFY115 while it resulted up-regulated in SFY114 (Fig. 2).

\section{Effects of drug-resistance on adherence, hydrophobicity and biofilm production}

Adherence to host surfaces is a required feature for initial colonization and for biofilm formation in yeasts. In order to understand if the drug resistance could affect the adherences, hydrophobicity and biofilm formation, we examined in the susceptible (DSY562) and resistant (SFY114, SFY115) strains of $C$. glabrata the adherence ability on plastic surface, the hydrophobicity and biofilm formation by a semi quantitative Cristal violet assay (CVA). As shown in Fig. 3A, the three strains behaved differently in their ability to adhere; in particular, SFY115 strain showed a reduction in adherence of about the $60 \%$ compared to the other two strains. It was reasonable to expect that the distribution and composition of the molecules involved in the adhesion events were differently modulated among the three strains. Indeed, CSH values obtained by a twophase system showed that the resistant strains SFY114 and SFY115 resulted to be less hydrophobic than the susceptible parental counterpart DSY562, with a reduction of about 40 and $50 \%$, respectively (Fig. 3A). The results obtained clearly demonstrate that the drug resistance feature reflects a marked difference in the cell wall composition of these strains. In particular, the resistant strain SFY115 showed an evident decrease in hydrophobicity when compared to the parental strain DSY562, suggesting a general down regulation of many proteins of the cell wall deputed to adhesion. Fig. 3B shows the results of biofilm formation in resistant strains (SFY114, SFY115) compared to the sensitive strain DSY562, at 24 and $48 \mathrm{~h}$ in CV assay. In the first $24 \mathrm{~h}$ of biofilm formation, SFY115 exhibited an increase of about $50 \%$ of biofilm formation in comparison to the sensitive strain DSY562 and the resistant strain SFY114. Moreover, after $48 \mathrm{~h}$ of biofilm formation when the biofilm was mature, a marked low increase in biofilm formation was accounted for SFY115, while for the strains DSY562 and SFY114 the biofilm growth was almost triplicated, in fairly agreement with the adherence data (Fig. 3A).

\section{Content of polysaccharides}

The fungal cell wall is a plastic and dynamic structure that constantly changes in response to environmental signals, with a number of highly efficient compensatory mechanisms. Therefore, we analysed the cells of the three strains in search for any variation in the major cell wall components. As shown in Table 2, the total glucose amount in DSY562 and SFY114 strains is similar, while a halved quantity can be observed in SFY115. Regarding 
Table 1 Summary of spots obtained from DSY562, SFY114 and SFY115 2DE and mass spectrometry analysis

\begin{tabular}{|c|c|c|c|c|c|c|c|c|c|c|}
\hline \multirow[b]{2}{*}{ \# spot } & \multicolumn{3}{|c|}{ Regulation } & \multirow{2}{*}{$\begin{array}{l}\text { Accession- } \\
\text { number }\end{array}$} & \multirow{2}{*}{$\begin{array}{l}\text { Proteinname } \\
\text { (molecularfunc- } \\
\text { tion) }\end{array}$} & \multirow[b]{2}{*}{ Gene name } & \multirow[b]{2}{*}{ Score } & \multirow[b]{2}{*}{ Coverage (\%) } & \multirow{2}{*}{$\begin{array}{c}\mathrm{MW} \\
{[\mathrm{kDa}]}\end{array}$} & \multirow[b]{2}{*}{$\mathrm{pl}$} \\
\hline & DSY562 & SFY114 & SFY115 & & & & & & & \\
\hline ssp2702 & + & + & ++ & Q6FTSO & $\begin{array}{l}\text { Similar to } \\
\text { uniprot|P15703 } \\
\text { Saccharomy- } \\
\text { ces cerevisiae } \\
\text { YGR282c BGL2 } \\
\text { (hydrolase activ- } \\
\text { ity, hydrolyzing } \\
\text { O-glycosyl } \\
\text { compounds) }\end{array}$ & CAGLOG00220g & 21.95 & 26.62 & 33.7 & 4.6 \\
\hline ssp3902 & + & +++ & - & Q8TG07 & $\begin{array}{l}\text { Lysophos- } \\
\text { pholipase } 1 \\
\text { (lysophospholi- } \\
\text { paseactivity) }\end{array}$ & PLB1 & 90.56 & 20.49 & 71.6 & 4.86 \\
\hline ssp6404 & + & - & -- & Q6FUX8 & $\begin{array}{l}\text { Strain CBS138 } \\
\text { chromosome } \\
\text { E complete } \\
\text { sequence (phos- } \\
\text { phoglyceratemu- } \\
\text { tase activity) }\end{array}$ & CAGL0E06358g & 319.63 & 19.84 & 27.6 & 7.06 \\
\hline ssp7401 & + & -- & --- & Q6FWL5 & $\begin{array}{l}\text { Superoxidedis- } \\
\text { mutase [Cu-Zn] } \\
\text { (metal ionbind- } \\
\text { ing; superoxide- } \\
\text { dismutaseac- } \\
\text { tivity) }\end{array}$ & SOD1 & 99.15 & 87.66 & 15.7 & 6.27 \\
\hline ssp7502 & + & ++ & -- & Q6FTZ7 & $\begin{array}{l}\text { Strain CBS138 } \\
\text { chromosome } \\
\text { F complete } \\
\text { sequence (struc- } \\
\text { tural constituent } \\
\text { of cell wall) }\end{array}$ & CAGLOF07579g & 1048.88 & 40.09 & 20.7 & 7.4 \\
\hline ssp7802 & + & ++ & -- & Q6FUQ9 & $\begin{array}{l}\text { Strain CBS138 } \\
\text { chromosome } \\
\text { F complete } \\
\text { sequence (struc- } \\
\text { tural constituent } \\
\text { of cell wall) }\end{array}$ & CAGLOF01463g & 80.37 & 9.05 & 21.4 & 7.4 \\
\hline
\end{tabular}

Notes: Regulation of relative intensities was calculated from statistical analysis performed with PDQuest software; symbols stay for: +, control; ++ up-regulated, +++ moderately up-regulated, - down-regulated, -- moderately down-regulated, --- strongly down-regulated. In the table are listed the following parameters: alphanumeric unique protein sequence identifier (Accession) provided by UniProtKB/Swiss-Prot protein Knowledgebase, Protein name (and Gene Ontology molecular function), Gene name, protein identification's SEQUEST HT Score, percentage of protein sequence covered by identified peptides (Coverage), theoretical Molecular Weight (in kiloDalton) and pl.

the total cell wall polysaccharides content, the two drugresistant strains show a similar behaviour when compared to the parental strain. However, there is a marked relative decrease of the cell wall alkali-acid insoluble constituents, which is mostly due to $\beta$ 1, 3-glucan. In particular, the content of the alkali-acid insoluble material per equal cell wall preparation amount of the SFY114 strain was less than half that of the parental, drug-susceptible strain (Table 2).

It was interesting to note that relative amounts of glucose and alkali-acid insoluble material ( $\beta$ 1, 3-glucan) is inverted in the two resistant strains, while the total polysaccharide amount results is similar. From a functional point of view, the two resistant strains behave differently, being SFY114 more adherent than SFY115. This aspect suggests that both strains lower the amount of the $\beta$ 1,3-glucan and its precursor (glucose) as compensatory cell wall mechanism.

\section{Discussion}

Candida glabrata is commensal yeast that has emerged as an important opportunistic pathogen and has become the second most common cause of candidiasis after Candida albicans. Moreover, C. glabrata intrinsically displays reduced susceptibility to azole drugs and shows a high propensity to developed secondary resistance. ${ }^{6}$ In the present study, we have carried out a comprehensive analysis in order to identify molecular characteristics and differences in C. glabrata cells of the cell wall yeast associated with azole-based drugs resistance. To get insights into the complex mechanism of the acquired resistance, we selected one azole-sensitive and two azole-resistant yeast strains.

The protein profile of the resistant strains was compared to the sensitive counterpart by a 2-DE/mass spectrometry combined proteomic approach supported by a database search to identify the differentially expressed proteins. This analysis highlighted the modulation of six proteins between the resistant and sensitive conditions; four of these proteins (Q6FTS0, Q8TG0, Q6FTZ7, Q6FUQ9) are termed by GO cellular compartment classification as cell wall secreted, extracellular and fungal-type cell wall. Q6FTZ7 (gene name: CAGL0F07579 g) has been previously described as 

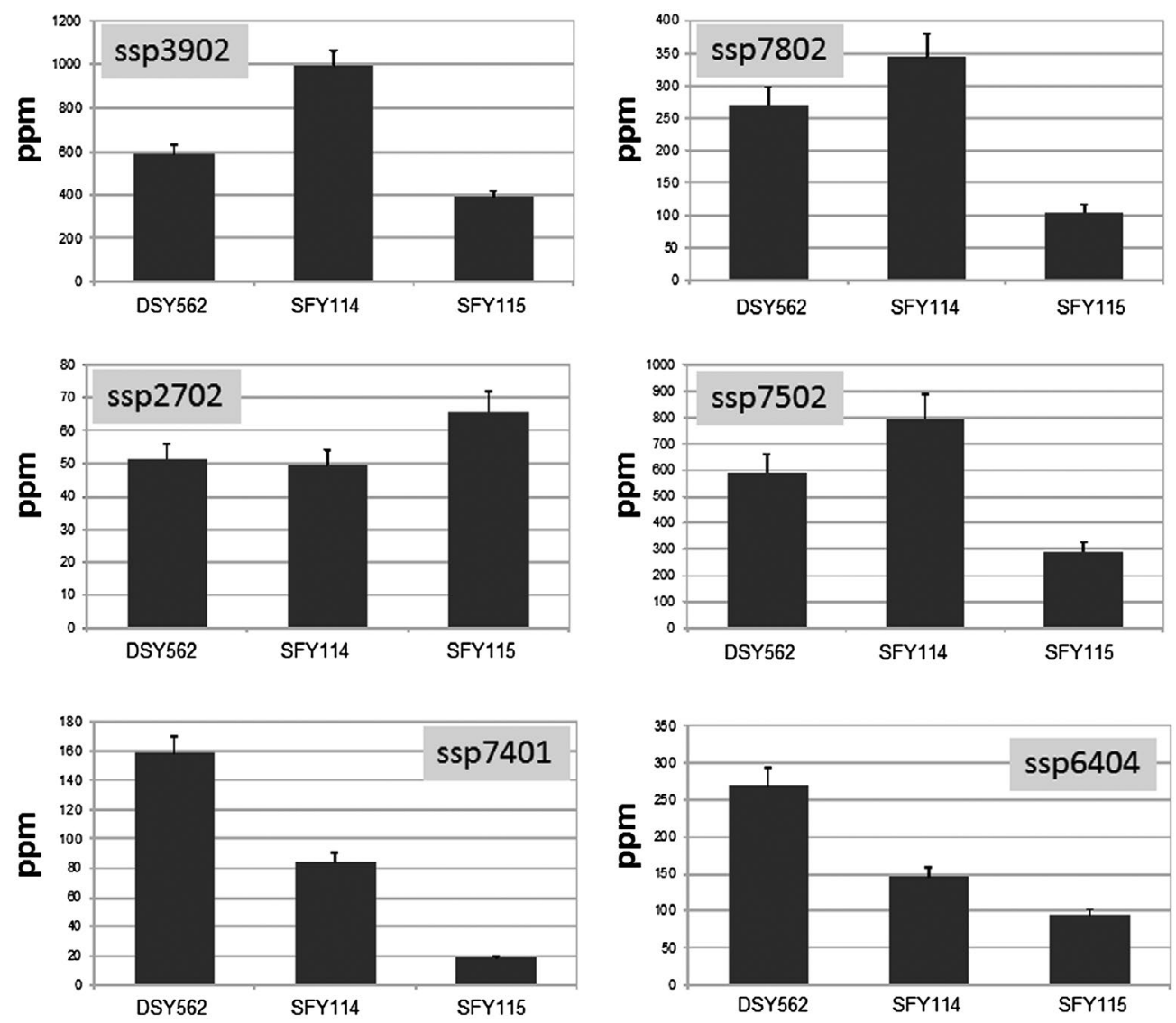

Figure 2 Histogram plot of statistical protein spot differences between the DSY562, SFY114 and SFY115 yeast strains. Polypeptide quantities were calculated in parts per million of the total integrated spot optical density ( $y$-axis). Average and standard deviation (as error bars) of each differentially regulated protein spot are shown.

glycosyl-phosphatidylinositol-modified (GPI) protein and it is one of the main components of $C$. glabrata cell wall in an 'in silico' and proteomic investigation. ${ }^{29}$ Moreover, two other proteins, Q6FUQ9 (CAGL0F01463g) and Q6FTS0 (CAGL0G00220g) were also described by Weig et coworkers as a GPI structural cell wall protein and a covalent bound CWP belonging to glycoside hydrolase family 17 , respectively. In the abundant family of $S$. cerevisiae Q6FTZ7 is homologous to Cwp1p and Q6FUQ9 GPI CWPs to Srp1p/Tip1p; whereas Q6FTS0 is homologous to Bgl2p from $S$. cerevisiae. The $\mathrm{Cwp} 1 \mathrm{p}$ and $\mathrm{Bgl} 2 \mathrm{p}$ transcripts were described as up-regulated after a transient cell wall damage. ${ }^{30}$ Identification of CWPs by gel-based methods is difficult, because CWPs are heavily glycosylated and often also phosphorylated, therefore, they give rise to different forms of the same protein. The evidence that spots 7502 and 7802 have apparent higher molecular masses (80 and $30 \mathrm{kDa}$, respectively) than the theoretical molecular masses of the corresponding identified proteins (Q6FTZ7 and Q6FUQ9, respectively), as observed in the gel, may be due to the treatment utilized to isolate cell wall proteins: Zymolyase cuts the glycosidic links among cell wall sugars but is not able to cut the mannose-proteins linkages that give rise to different glycosylated forms of the same protein, resulting different apparent isoforms. The remaining O-linked carbohydrate side-chains may indeed, contain mannosyl-phosphate groups, which confer both higher masses and negative character to the protein. Therefore, Q6FTZ7 (CAGL0F07579g) and Q6FUQ9 (CAGL0F01463g) were identified by LC-MS/MS in C. glabrata biofilms as structural mannoprotein and mannoprotein of the Srp1p/Tip1p family, respectively. ${ }^{31}$ The up-regulation of these proteins in SFY114 may be correlated with the higher adherence propensity of this strain compared to the SFY115, where the same proteins were down-regulated. Lysophopspholypase 1 (Q8TG07, PLB1), up-regulated in SFY114 and downregulated in SFY115, was also identified as C. glabrata GPI CWP by GPI algorithm and belongs to the Phospholipase B class of well-known plasma-membrane-localized fungal GPI proteins..$^{29}$ This protein was also described as a component of the cell wall of $C$. albicans. ${ }^{32}$ The expression of phospholipase B1 mRNA and protein (both of secreted and intracellular forms) were found to be higher in fluconazole resistant strains than in susceptible strains of $C$. albicans. ${ }^{33}$ Phospholipase $B$ catalyzes the release of fatty acids from lysophospholipids and may as well contribute to pathogenicity by helping fungi in damaging and traversing host cell membranes, two processes which likely increase the rapidity of disseminated infection. PLB activity is an important determinant of the virulence of several fungi, including C. albicans, Cryptococcus neoformans and Aspergillus fumigates. ${ }^{34}$

Two out of six differentially expressed proteins are described by Gene Ontology as cytosolic ones: the 

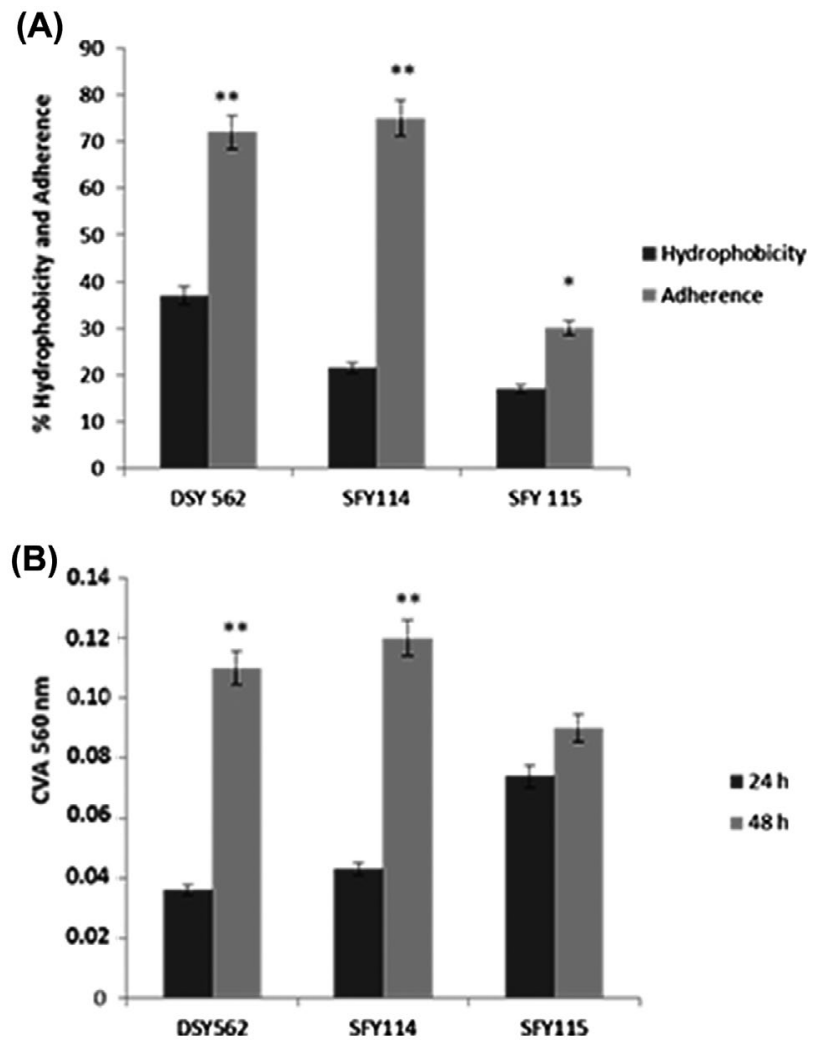

Figure 3 Adherence, hydrophobicity and biofilm formation of C. glabrata strains DSY562, SFY114 and SFY115. (A) Percentage of plastic adherent cells and cell surface hydrophobicity values measured with a two phase system. (B) Istograms of Cristal violet assay (CVA) values after 24 and $48 \mathrm{~h}$ of biofilm formation. Mean values of \% hydrophobicity and adherence \pm SD and biofilm formation \pm SD of three independent experiments are shown; $\left({ }^{*}\right) p<0.05$ is considered statistically significant and $\left(^{* *}\right)$ $p<0.001$ highly significant.

Phosphoglycerate mutase Q6FUX8 and the Superoxide dismutase Q6FWL5 (ssp6404 and 7401, respectively; down-regulated in both resistant strains); however these two proteins have already been described as present in cell wall of other fungi. ${ }^{35-37}$ Both proteins were also identified as modulated azole-resistant $C$. glabrata cytosolic proteins. ${ }^{38}$ Interestingly, in the same study, Phosphoglycerate mutase was identified as down-expressed in the mutant azole-resistant yeast culture compared to susceptible wildtype isolate, suggesting a corresponding decrease in the metabolic rate and down-regulation of the carbohydrate metabolism.

Superoxide dismutase $[\mathrm{Cu}-\mathrm{Zn}]$ was reported by Loureiro $^{38}$ as up-regulated cytosolic protein in azole-resistant mutant strain; while in our study a down-expression of CW SOD occurred in both resistant strains. Miconazole and Fluconazole are known to induce the production of endogenous reactive oxygen species (ROS) in Candida species, and, in multiple clinical isolates, azole-induced ROS production was suggest as a mechanism of action of these drugs. ${ }^{39}$ These data suggest a role for ROS production and enhanced susceptibility to oxidative damage in the cells. A lower presence of SOD1 in the cell wall of SFY114 and SFY115 isolates could be explained by a greater displacement in the cytoplasm of SOD1 total fungus pool. These results are in agreement with previous data. ${ }^{40}$ stating how the resistance to fluconazole has a protective role against ROS in C. albicans.

Antimicrobial drugs may be included as possible agents that affect the adhesion process altering the microbial cell surface involved in the interaction. ${ }^{41}$ Castano et al. ${ }^{14}$ reported that the adherence of $C$. glabrata to human epithelial cells is mediated by multiple mechanisms, including electrostatic, hydrophobic and specific adhesin-receptor mediated interactions. In C. glabrata, this interaction depends on the expression of EPA, which encodes a lectin

Table 2 Cell wall composition of drug-susceptible and resistant C. glabrata strains

\begin{tabular}{|c|c|c|c|}
\hline Strains & $\%$ Glucose $^{a}$ & $\%$ Cell wall ${ }^{\mathrm{b}}$ & $\%$ Alkali-acid insoluble ${ }^{c}$ \\
\hline DSY562 & $54.5 \pm 4.95$ & $10.4 \pm 0.56$ & $32 \pm 2.12$ \\
\hline SFY114 & $54.4 \pm 2.12$ & $13.1 \pm 1.55$ & $6.6 \pm 0.28$ \\
\hline SFY115 & $27.2 \pm 1.69$ & $8.7 \pm 0.91$ & $25 \pm 0.70$ \\
\hline
\end{tabular}

aExpressed as a percentage of cell dry weight and measured by the method of Dubois et al.

bexpressed as a percentage of cell dry weight.

cExpressed as a percentage of alkali-acid-insoluble cell wall material/milligram of cell wall dry weight. 
belonging to a family of GPI-anchored glucan cross-linked cell wall proteins, ${ }^{42}$ furthermore, fungal $\mathrm{CSH}$ may play an important role in pathogenesis and is mediated by mannoproteins associated to cell wall. In this study, we have evaluated the adherence to plastic surface, and the hydrophobicity in the susceptible (DSY562) and resistant (SFY114 and SFY115) strains of C. glabrata. Our results (Fig. 3A) show a modulation of adherence and hydrophobic values in drug-resistant strains in comparison to the parental strains DSY562. In particular, it is possible to observe, only in the resistant strain SFY115, a fall of about $50 \%$ both adherence and hydrophobicity values. These data are in agreement with the proteomic analyses, where many proteins in this strain are down-regulated, as well as the phospho-glyceratemutase that contributes to host cell attachment. ${ }^{43}$ Microbial biofilms play an important role in human diseases, it is now estimated that $65 \%$ of microbial infections are caused by micro-organisms growing on surface rather than in the free living planktonic state..$^{44,45}$ In $C$. parapsilosis and $C$. glabrata, $\mathrm{CSH}$ measurement represents a simple and reliable method to predict biofilm formation. ${ }^{46}$ So, in agreement with the results obtained for the hydrophobicity and adherence, in the resistant strain SFY115 (Fig. 3B) the biofilm formation decreased in comparison to the parental strain DSY562. Conversely, no significant differences were reported in cell wall proteins of the resistant strain SFY114 compared to the parental strain DSY562. More probably, these differences between the two resistant strains may be ascribed in the different mutations to azoles resistance, pdr1D-PDR1 and pdr1DL280F for strains SFY114 and SFY115, respectively.

In a previous study, we showed that a different content in the major cell wall polysaccharides was present in resistant strains CO23RFK and CO23RFLU of C. albicans compares to susceptible strains $\mathrm{CO} 23 .{ }^{47,48}$ To assess if similar changes occurred as well in the cell wall of $C$. glabrata, we examined the whole cell wall polysaccharides content of the three strains DSY562, SFY115 and SFY114. Similarly to the protein content, it is possible to observe a marked alteration also in the distribution of the major polysaccharides of the cell wall in the SYF115 resistant strain (Table 2). On the other hand, in resistant strain SFY114 only the amount of the alkali-acid-insoluble material - mainly represented by mannoproteins - is decreased. This material substantially corresponds to the glucan interwoven fibrillar constituent of the cell wall; it is bound to chitin and confers rigidity and resistance to the cell wall itself. ${ }^{49}$ The differences described in the distribution of the major cell wall components in the strain SYF115 may be thus involved in the decrease of adherence, hydrophobicity and biofilm formation. Our results clearly show the tendency of resistant strains to modify the cell wall, with a modulation of the cell wall proteins, adherence, hydrophobicity, biofilm formation and polysaccharides content. These aspects suggest a close relationship between cell wall modulation and drug resistance, even though this modulation is not same in the two resistant strains SF114 and SF115. Nonetheless, further studies are needed to validate this hypothesis and to understand the relationship between drug resistance and modification of cell wall of the human opportunistic pathogen $C$. glabrata.

\section{Supplementary material}

The supplementary material for this paper is available online at http://dx.doi.10.1080/1120009X.2016.1199507.

\section{Conflict of interest}

No conflict of interest.

\section{Acknowledgement}

The authors are grateful to Prof. Maurizio Sanguinetti to kindly supply C. glabrata strains and Cristina Buffone to editorial assistance.

\section{ORCID}

Letizia Angiolella (D) http://orcid.org/0000-0002-0473-5587

\section{References}

1 Pfaller MA, Diekema DJ, Gibbs DL, Newell VA, Ellis D, Tullio V, et al, Global antifungal surveillance group. Results from the ARTEMIS DISK Global Antifungal Surveillance Study, 1997 to 2007: a 10.5year analysis of susceptibilities of Candida species to fluconazole and voriconazole as determined by CLSI standardized disk diffusion. J Clin Microbiol. 2010;48:1366-1377.

2 Pfaller MA, Diekema DJ. Epidemiology of invasive candidiasis: a persistent public health problem. Clin Microbiol Rev. 2007;20 133-163.

3 Csank C, Haynes K. Candida glabrata displays pseudohyphal growth. FEMS Microbiol Lett. 2000;189:115-120.

4 Fidel PL Jr, Vazquez JA, Sobel JD. Candida glabrata: review of epidemiology, pathogenesis, and clinical disease with comparison to C. albicans. Clin Microbiol Rev. 1999;12:80-96.

5 Chapeland-Leclerc F, Hennequin C, Papon N, Noël T, Girard A, Socié $\mathrm{G}$, et al. Acquisition of flucytosine, azole, and caspofungin resistance in Candida glabrata bloodstream isolates serially obtained from a hematopoietic stem cell transplant recipient. Antimicrob Agents Chemother. 2010;54:1360-1362.

6 Pfaller MA, Diekema DJ. The epidemiology of invasive candidiasis. In: Calderone RA, Clancy CJ, editors. Candida and candidiasis. 2nd ed. Washington, DC: ASM Press; 2012. p. 449-480.

7 de Groot PW, Kraneveld EA, Yin QY, Dekker HL, Gross U, Crielaard $\mathrm{W}$, et al. The cell wall of the human pathogen Candida glabrata: differential incorporation of novel adhesin-like wall proteins. Eukaryot Cell. 2008;7:1951-1964.

8 West L, Lowman DW, Mora-Montes HM, Grubb S, Murdoch C, Thornhill $\mathrm{MH}$, et al. Differential virulence of Candida glabrata Glycosylation mutants. J Biol Chem. 2013;288:22006-18.

9 Mora-Montes HM, McKenzie C, Bain JM, Lewis LE, Erwig LP, Gow NA. Interactions between macrophages and cell wall oligosaccharides of Candida albicans. Methods Mol Biol. 2012;845:247-260.

10 Nobile CJ, Andes DR, Nett JE, Smith FJ, Yue F, Phan QT, et al. Critical role of Bcrl-dependent adhesins in $C$. albicans biofilm formation in vitro and in vivo. PLoS Pathog. 2006;2:e63.

11 Calderone RA, Brown PC. Adherence and receptor relationship of Candida albicans. Microbiol Rev. 1991;55:1-20.

12 Hazen KC. Participation of yeast cell surface hydrophobicity in adherence of Candida albicans to human epithelial cells. Infect Immun. 1989:57:1894-1900.

13 Halliwell SC, Smith MC, Muston P, Holland SL, Avery SV. Heterogeneous expression of the virulence-related adhesin Epa1 between individual cells and strains of the pathogen Candida glabrata. Eukaryot Cell. 2012;11:141-150.

14 Castaño I, Pan SJ, Zupancic M, Hennequin C, Dujon B, Cormack BP. Telomere length control and transcriptional regulation of 
subtelomericadhesins in Candida glabrata. Mol Microbiol. 2005;5:246-258.

15 Domergue R, Castaño I, De Las Penãs A, Zupanic M, Lockatell V, Hebel JR. Nicotinic acid limitation regulates silencing of Candida adhesins during UTI. Science. 2005;308:866-870.

16 Iraqui I, Garcia-Sanchez S, Aubert S, Dromer F, Ghigo GM, D’Enfert G, Jambon G. The YAK1p kinase control expression of adhesins and biofilm formation in Candida glabrata in a Sir4p-dependent pathway. Mol Microbiol. 2005;55:1259-1271.

17 Kucharıkova S, Tournu H, Lagrou K, Van Dijck P, Bujdakova H. Detailed comparison of Candida albicans and Candida glabrata biofilms under different conditions and their susceptibility to caspofungin and anidulafungin. J Med Microbiol. 2011;60:1261-1269.

18 Blankenship JR, Mitchell AP. How to build a biofilm: a fungal perspective. Curr Opin Microbiol. 2006;9:588-594.

19 Seneviratne CJ, Silva WJ, Jin LJ, Samaranayake HS, Samaranayake LP. Architectural analysis, viability assessment and growth kinetics of Candida albicans and Candida glabrata biofilms. Arch Oral Biol. 2009;54:1052-1060.

20 Silva S, Henriques M, Martins A, Oliveira R, Williams D, Azeredo J. Biofilms of non-Candida albicans Candida species: quantification, structure and matrix composition. Med Mycol. 2009;47:681-689.

21 Ferrari S, Ischer F, Calabrese D, Posteraro B, Sanguinetti M, Fadda G, Rohde R, Bauser C, Bader O, Sanglard D. Gain of function mutations in CgPDR1 of Candida glabrata not only mediate antifungal resistance but also enhance virulence. PLoS Pathog. 2009;5:e1000268.

22 Angiolella L, Facchin M, Stringaro A, Maras B, Simonetti N, Cassone A. Identification of a glucan-associated enolase as a main cell wall protein of Candida albicans and an indirect target of lipopeptideantimycotics. J Infect Dis. 1996;173:684-690.

23 Panfoli I, Calzia D, Santucci L, Ravera S, Bruschi M, Candiano G. A blue dive: from 'blue fingers' to 'blue silver'. A comparative overview of staining methods for in-gel proteomics. Expert Rev Proteomics. 2012;9:627-634.

24 Peeters E, Nelis HJ, Coenye T. Comparison of multiple methods for quantification of microbial biofilms grown in microtiter plates. J Microbiol Meth. 2008;72:157-165

25 Fleet GH, Manners DJ. Isolation and composition of an alkalisoluble glucan from the cell wall of Saccharomyces cerevisiae. J. Gen. Microbiol. 1976;94:80-92.

26 Fleet GH, Manners DJ. The enzymatic degradation of an alkalisoluble glucan from the cell walls of Saccharomyces cerevisiae. J. Gen. Microbiol. 1977;98:315-327.

27 Dubois M, Giles KA, Hamilton JK, Rebers PA, Smith F. Colorimetric method for determination of sugars and related substances. Anal Chem. 1956;28:350-56.

$28 \mathrm{He}$ M, Du M, Fan M, Bian Z. In vitro activity of eugenol against Candida albicans biofilms. Mycopathologia. 2007;163:137-143.

29 Weig M, Jansch L, Gross U, De Koster CG, Klis FM, De Groo PW. Systematic identification in silico of covalently bound cell wall proteins and analysis of protein-polysaccharide linkages of the human pathogen Candida glabrata. Microbiology. 2004;150:3129-3144.

30 Garcia R, Bermejo C, Grau C, Perez R, Rodriguez-Pena JM, Francois $\mathrm{J}$, et al. The global transcriptional response to transient cell wal damage in Saccharomyces cerevisiae and its regulation by the cell integrity signaling pathway. J Biol Chem. 2004;279:15183-15195.

31 Kraneveld EA, de Soet JJ, Deng DM, Dekker HL, de Koster CG, Klis FM, et al. Identification and differential gene expression of adhesinlike wall proteins in Candida glabrata biofilms. Mycopathologia. 2011:172:415-427.
32 Chaffin WL, Lopez-Ribot JL, Casanova M, Gozalbo D, Martinez JP. Cell wall and secreted proteins of Candida albicans: identification, function, and expression. Microbiol Mol Biol Rev. 1998;62:130-180.

33 Ying S, Chunyang L. Correlation between phospholipase of Candida albicans and resistance to fluconazole. Mycoses. 2012;55:50-55.

34 Ghannoum MA. Potential role of phospholipases in virulence and fungal pathogenesis. Clin Microbiol Rev. 2000;13:122-143.

35 Hamilton AJ, Holdom MD, Jeavons L. Expression of the $\mathrm{Cu}, \mathrm{Zn}$ superoxide dismutase of Aspergillusfumigatus as determined by immunochemistry and immunoelectron microscopy. FEMS Immunol Med Microbiol. 1996;14:95-102.

36 Motshwene P, Brandt W, Lindsey G. Significant quantities of the glycolytic enzyme phosphoglycerate mutase are present in the cell wall of yeast Saccharomyces cerevisiae. Biochem J. 2003;369:357-362.

37 Karkowska-Kuleta J, Kedracka-Krok S, Rapala-Kozik M, Kamysz W, Bielinska S, Karafova A, Kozik A. Molecular determinants of the interaction between human high molecular weight kininogen and Candida albicans cell wall: Identification of kininogen-binding proteins on fungal cell wall and mapping the cell wall-binding regions on kininogen molecule. Peptides. 2011;32:2488-2496.

38 Loureiro YPCV, Kubitschek PH, Larcher G, Perales J, Rodriguez Leon I, Lopes-Bezerra LM, Bouchara JP. Proteomic analysis of cytosolic proteins associated with petite mutations in Candida glabrata. Braz J Med Biol Res. 2010;43:1203-1214.

39 Kobayashi D, Kondo K, Uehara N, Otokozawa S, Tsuji N, Yagihashi A, Watanabe N. Endogenous reactive oxygen species is an important mediator of miconazole antifungal effect. Antimicrob Agents Chemother. 2002;46:3113-3117.

40 Maras B, Angiolella L, Mignogna G, Vavala E, Macone A, Colone M, et al. Glutathione metabolism in Candida albicans resistant strains to fluconazole and micafungin. PLoS One. 2014;9(6):e98387.

41 Kyselgof G, Sandovsky-Losica H, Berdicevsky I, Segal E. Caspofungin affects adhesion of Candida to a human cell line. JMycol Med. 2007;17:1-7.

42 Frieman MB, McCaffery JM, Cormack BP. Modular domain structure in the Candida glabrataadhesin Epa1p, a $\beta 1.6$ glucan- cross-linked cell wall protein. Mol Microbiol. 2002;46:479-492.

43 Lopez CM, Wallich R, Riesbeck K, Skerka C, Zipfe PF. Candida albicans uses the surface protein $\mathrm{Gpm} 1$ to attach to human endothelial cells and to keratinocytes via the adhesive protein vitronectin. PLoS One. 2014;9(3):e90796.

44 Douglas LJ. Medical importance of biofilms in Candida infections. Rev Iberoam Micol. 2002;19:139-143.

45 Douglas LJ. Candida biofilms and their role in infection. Trends Microbiol. 2003;11:30-36.

46 Borghi E, Sciota R, Biassoni C, Cirasola D, Cappelletti L, Vizzini L, et al. Cell surface hydrophobicity: a predictor of biofilm production in Candida isolates. J Med Microbiol. 2011;60:689-690.

47 Angiolella L, Maras B, Stringaro AR, Arancia G, Mondello F, Girolamo $\mathrm{A}$, et al. Glucan-associated protein modulations and ultrastructural changes of the cell wall in Candida albicans treated with micafungin, a water-soluble, lipopeptideantimycotic. J Chemother. 2005;17:409416.

48 Angiolella L, Stringaro AR, De Bernardis F, Posteraro B, Bonito $\mathrm{M}$, Toccacieli L, et al. Increase of virulence and its phenotypic trait in drug-resistant strains of Candida albicans. Antimicrob Agents Chemoter. 2008;52:927-936.

49 Gow NA, Brown AJ, Odds FC. Fungal morphogenesis and host invasion. Curr Opin Microbiol. 2002;5:366-371. 